\title{
FAKTOR-FAKTOR YANG MEMPENGARUHI TINGKAT KESEJAHTERAAN PETANI SAWIT DI KECAMATAN GUNUNG MERIAH KABUPATEN ACEH SINGKIL
}

Munardi $^{\mathrm{a}^{*}}$, Diana Situmorang ${ }^{\mathrm{a}^{*}}$

${ }^{a}$ Fakultas Ekonomi dan Bisnis Universitas Malikussaleh

*Corresponding author: munardi@unimal.ac.id

*dianasitumorang11@yahoo.co.id

Keywords:

Capital, Revenue, Palm Farmers.
The purpose of this study is to examine the effect of capital, land area, and income on the level of welfare of oil palm farmers in the Gunung Meriah District of Aceh Singkil Regency. The data used in this study are primary data obtained from 96 respondents. The method uses is a multiple linear regression model. The results show that capital, land area and income of oil palm farmers influence the level of welfare of oil palm farmers in Gunung Meriah District, Aceh Singkil Regency.

\section{PENDAHULUAN}

Indonesia merupakan negara agraris yang dimana pertanian masih menjadi pilar penting di aspek kehidupan dan perekonomian penduduknya. Dari 240 juta jiwa penduduk Indonesia lebih dari 46 persennya bekerja di bidang pertanian. Bidang pertanian ini bukan hanya di gunakan menyediakan kebutuhan pangan bagi penduduknya yang cukup besar namun juga mendominasi kegiatan ekspor negara ini. Salah satu produksi perkebunan terbesar Indonesia saat ini adalah kelapa sawit. Produksi kelapa sawit Indonesia sekarang ini memenuhi 40 persen kebutuhan konsumsi dunia. Bidang pertanian ini menjadi bidang yangsangat menunjang bagi perekonomian Indonesia dan menyumbang devisa bagi negara. (Gurnita, 2016:3)

Indonesia di juluki dengan negara agraris karena indonesia memiliki hasil alam yang berlimpah salah satunya di bidang pertanian, indoensia memiliki 74,52 persen lahan pertanian dan 25,48 persen di gunakan sebagai lahan industri, permukiman dan lainnya (statistik, 2004).

Pertanian memiliki peranan yang sangat besar untuk kelangsungan hidup masyarakat di indonesia. Maka perlu di perhatikan kebijakankebijakan yang ada agar hasil pertanian di indonesia lebih maju dan meningkat. Tentunya sebagai sebuah negara kepulauan, indonesia memiliki banyak Provinsi dengan segala keberagamannya, salah satunya ialah provinsi Aceh. Provinsi ini memiliki kekayaan alam yang luar biasa banyak, sehingga di berikan hak otoritas yang di khususkan. Kekayaan alam yang di miliki oleh Aceh sangat beragam salah satunya yaitu kelapa sawit merupakan tumbuhan industri yang penting penghasilan minyak masak, minyak industri, maupun bahan bakar.

Dengan adanya pembukaan lahan-lahan ini maka banyak Perusahaan kelapa Sawit Swasta yang membuka investasinya untuk mengelola lahan perkebunan dan pembangunan pabrik pengolahan kelapa sawit khususnya di Kecamatan Gunung Meriah. Sampai saat ini, berdasarkan data Dinas perkebunan dan kehutanan Kabupaten Aceh Singkil beberapa perusahaan Perkebunan Kelapa Sawit tersebut masih terus beroperasi dan telah melakukan penanaman dengan jumlah lahan yang sangat luas seperti ditunjukkan tabel dibawah ini:

Tabel 1.1

Nama-Nama Perusahaan Kelapa Sawit di Kabupaten Aceh Singkil

\begin{tabular}{|c|l|c|c|c|c|}
\hline No & $\begin{array}{c}\text { Nama } \\
\text { Perusah } \\
\text { aan }\end{array}$ & $\begin{array}{c}\text { Keca } \\
\text { mata } \\
\mathrm{n}\end{array}$ & $\begin{array}{c}\text { Jeni } \\
\text { sKo } \\
\text { mu } \\
\text { diti }\end{array}$ & $\begin{array}{c}\text { Luas } \\
\text { Konses } \\
\mathrm{i}(\mathrm{Ha})\end{array}$ & $\begin{array}{c}\text { Luasreal } \\
\text { Tanaman } \\
\text { (Ha) }\end{array}$ \\
\hline 1. & $\begin{array}{l}\text { PT. } \\
\text { Socfind }\end{array}$ & $\begin{array}{c}\text { Gun } \\
\text { ung }\end{array}$ & $\begin{array}{c}\text { Kel } \\
\text { apa }\end{array}$ & $\begin{array}{c}4414,1 \\
8\end{array}$ & 4210 \\
\hline
\end{tabular}




\begin{tabular}{|c|c|c|c|c|c|}
\hline & o & $\begin{array}{l}\text { Meri } \\
\text { ah }\end{array}$ & $\begin{array}{l}\mathrm{Sa} \\
\text { wit }\end{array}$ & & \\
\hline 2. & $\begin{array}{l}\text { PT. } \\
\text { Lemba } \\
\text { h Bakti }\end{array}$ & $\begin{array}{l}\text { Sing } \\
\text { kil } \\
\text { Utar } \\
\text { a }\end{array}$ & $\begin{array}{l}\text { Kel } \\
\text { apa } \\
\mathrm{Sa} \\
\text { wit }\end{array}$ & 6570 & 5923 \\
\hline 3. & $\begin{array}{l}\text { PT. } \\
\text { Delima } \\
\text { Makmu } \\
\mathrm{r}\end{array}$ & $\begin{array}{l}\text { Dan } \\
\text { au } \\
\text { Paris }\end{array}$ & $\begin{array}{l}\text { Kel } \\
\text { apa } \\
\text { Sa } \\
\text { wit }\end{array}$ & $\begin{array}{c}12.173, \\
47\end{array}$ & 8969 \\
\hline 4. & $\begin{array}{l}\text { PT. } \\
\text { Ubertra } \\
\text { co }\end{array}$ & $\begin{array}{l}\text { Kota } \\
\text { baha } \\
\text { ru }\end{array}$ & $\begin{array}{l}\text { Kel } \\
\text { apa } \\
\text { Sa } \\
\text { wit }\end{array}$ & $\begin{array}{c}13.924 \\
68\end{array}$ & 5869 \\
\hline 5. & $\begin{array}{l}\text { Lestari } \\
\text { Tunggg } \\
\text { al } \\
\text { Pratam } \\
\text { a }\end{array}$ & $\begin{array}{l}\text { Dan } \\
\text { au } \\
\text { Paris }\end{array}$ & $\begin{array}{l}\text { Kel } \\
\text { apa } \\
\text { Sa } \\
\text { wit }\end{array}$ & 1861 & 1200 \\
\hline 6. & $\begin{array}{l}\text { PT. } \\
\text { Telaga } \\
\text { Zam- } \\
\text { zam }\end{array}$ & $\begin{array}{l}\text { Gun } \\
\text { ung } \\
\text { Meri } \\
\text { ah }\end{array}$ & $\begin{array}{l}\text { Kel } \\
\text { apa } \\
\text { Sa } \\
\text { wit }\end{array}$ & 100,05 & 100,05 \\
\hline 7. & $\begin{array}{l}\text { PT. } \\
\text { Jaya } \\
\text { Bahni } \\
\text { Utama }\end{array}$ & $\begin{array}{l}\text { Dan } \\
\text { au } \\
\text { Paris }\end{array}$ & $\begin{array}{l}\text { Kel } \\
\text { apa } \\
\text { Sa } \\
\text { wit }\end{array}$ & 1800 & 1800 \\
\hline
\end{tabular}

Di kecamatan Gunung Meriah perkebunan sawit sudah tidak asing lagi selain perkebunan milik pribadi juga ada perkebunan yang di olah oleh perusahaan. Dengan besarnya hasil yang didapatkan dari perkebunan sawit ini menyebabkan masyarakat terdorong untuk terus mengembangkan areal perkebunan kelapa sawit. Sehingga di kecamatan Gunung Meriah masyarakat telah banyak merubah lahan yang awalnya tidak di fungsikan kini di pergunakan menjadi perkebunan sawit. Bisa dikatakan Kecamatan Gunung Meriah yang dulunya memiliki banyak lahan yang tidak di fungsikan sekarang sudah di pergunakan menjadi lahan perkebunan.

Penelitian sebelumya (Priyatno, 2010) dengan judul Analisis faktor-faktor yang mempengaruhi harga TBS dalam Meningatkan kesejahteraan petani sawit di Kabupaten labuhan batu menggunakan analisis regresi lenier berganda. Berdasarkan hasil analisis dapat disimpulkan bahwa tingkat kesejahteraan petani sawit di Kabupaten Labuhan Batu tidak semua menerima hasil produksi dari pertaniannya yang tinggi untuk kesejahteraannya.
Persamaan dengan penilitian ini adalah sama-sama membahas tentang kesejahteraan petani kelapa sawit dan sama-sama menggunakan liner berganda. Kemudian metode pengumpulan data yang sama yaitu dengan menggunakan data primer yang langsung didapat dari lapangan melalui kuesioner yang telah diisi oleh responden, namun perbedaan terlihat di pembahasan lokasi penelitian pada skripsi ini.

Berdasarkan latar belakang diatas, maka tujuan penelitian ini adalah:

1. Untuk mengertahui seberapa besar pengaruh modal terhadap pendapatan petani sawit di Kecamatan Gunung Meriah Kabupaten Aceh Singkil

2. Untuk mengetahui seberapa besar pengaruh luas lahan terhadap pendapatan petani di Kecamatan Gunung Meriah Kabupaten Aceh Singkil.

3. Untuk mengetahuai seberapa besar pengaruh modal dan luas lahan terhadap pendapatan petani sawit di Kecamatan Gunung Meriah Kabupaten Aceh Singkil

\section{TINJAUAN PUSTAKA}

Dalam Undang-Undang Tahun 2009 tentang kesejahteraan sosial di jelaskan bahwa kesejahteraan sosial adalah kondisi terpunuhinya kebutuhan material, sprtual, dan sosial bagi warga negara agar dapat hidup layak dan mampu mengembangkan diri, sehingga dapat melaksanakan fungsi sosial. Sedangkan penyelenggaraan kesejahteraan sosial adalah upaya yang terarah, terpadu, dan masyarkat dalam bentuk pelaynan sosial guna memenuh rehabilitas sosial, pemberdayaan sosial, dan perlindungan sosial (UU.No.11 tahun.2009 tentang kesejahteraan sosial)

(Sugiyono, 2007) dalam penelitiannya menjelaskan bahwa menurut badan pusat statistik, indikator yang di gunakan untuk mengetahui tingkat kesejahteraan ada delapan yaitu pendapatan, konsumsi atau pengeluaran keluarga, keadaan tempat tinggal, fasilitas tempat tinggal, kesehatan anggota keluarga, kemudahaan mendapatkan pelayanan kesehatan, kemudahaan memasukkan anak ke jenjang pendidikan, dan kemudahan mendapatkan pasilitas transportasi 


\section{Modal}

Menurut (Sukirno, 2002) modal dapat di artkan sebagai pengeluaran perusahaan untuk membeli barang-barang di modal dan perlengkapan -perlengkapan produksi untuk menambah kemampuan memproduksi barangbarang dan jasa-jasa yang tersedia dalam perekonomian.

\section{Luas Lahan}

Menurut (Harmanto, 2007) lahan ialah permukaan bumi yang dengan kekayaan berupa tanah, mineral, benda cair batuan, dan gas yang terkandung di dalamnya. Lahan di permukaan bumi ini meliputi mulai dari wilayah pantai sampai dengan daerah pegunungan. . Berdasakan penjelasan di atas maka kekayaan berupa tanah, mineral, benda cair, batuan, dan gas yang terkandung di dalamnya akan membantu tanaman kelapa sawit untuk berkembang dan luas lahan dalam penanaman kelapa sawit. Keduanya berkolerasi posotif di mana semakin luas lahan yang di gunkan untuk menanam kelapa sawit maka hasil yang di peroleh pun semakin banyak.

\section{Metode Penelitian Populasi dan Sample}

Yang menjadi populasi dalam penelitian ini adalah petani Kelapa Sawit di Kecamatan Gunung Meriah sebanyak 2160 orang.(Sumber : Gunung Meria Dalam Angka 2017)

Teknik pengambilan sample dalam penelitian ini menggunakan metode sample acak sederhana (Sample Random Sampling) sehingga di peroleh sample yang dapat mewakili (Representatif). Penentun jumlah sample yang digunakan pendekatan Slovin dengan perhitungan sebagi berikut

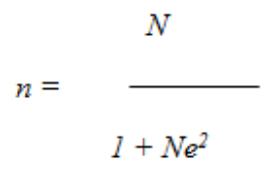

Dimana:

$$
\begin{array}{ll}
\mathrm{n} & =\text { Sample } \\
\mathrm{N} & =\text { Populasi } \\
\mathrm{e} & =\text { persentase } \\
1 & =\text { kostanta }
\end{array}
$$

Dengan demikian populasi sebesar 2160 petani dan sebesar 0,10 (10\%), maka jumlah sample minimal adalah:

$$
\begin{gathered}
n=\frac{2160}{1+2160(0,10)^{2}} \\
=95,57 \text { (di bulatkan menjadi } 96 \text { petani) }
\end{gathered}
$$

\section{Teknik Pengumpulan Data}

Dalam penelitian ini pelaksanaan metode pengumpulan data di maksudkan untuk mendapatkan bahan-bahan yang relavan terkait dengan permasalahaan yang diangkat dan akurat.Ada pun teknik pengumpulan data lain yang digunakan dalam penelitian ini, yaitu:

1. Penelitian kepustakaan Yaitu teknik pengumpulan data dengan cara mempelajari dan memahami buku-buku dana literatur yang ada hubungannya dengan masalah yang diteliti untuk dapat memperoleh bahanbahan yang akan dijadikan landasan pemikiran.

2. Penelitian lapangan Yaitu mengandalkan pengamatan langsung pada tempat yang diteliti yang dilakukan dengan teknik sebagi berikut:

a. Wawancara yaitu mengadakan tanya jawab secara langsung dengan pihak-pihak yang dianggap dapat memberikan informasi yang sesuai dengan kebetulan.

b. Kuesioner yaitu teknik pengumpulan data dengan cara menyebarkan daftar pertanyaan yang bersangkutan dengan masalah responden dengan tujuan memperoleh datadata yang dapat mendukung penelitian. Kuesioner jugaadalah alat pengumpulan data yang berupa daftar pertanyaan tertulis untuk memperoleh keterangan dari sejumlah responden atau dengan kata lain kuesioner yang digunakan dalam penelitian ini merupakan alat dari wawancara yang di gunakan kuesioner

c. Dokumentasi menganalisis data-data yang berupa dokumen-dokumen yang berasal dari Kecamatan Gunung Meriah yang berkaitan langsung dengan permasalahan penelitian.

\section{Definisi Operasional Variabel penelitian}

Untuk menghindari dari kesalahan dalam mengartikan variabel-variabel yang dianalisis 
untuk membatasi permasalahan dalam penelitian ini, perlu dijelaskan definisi dari operasional untuk masing-masing variabel. Variabel yang dirumuskan dalam penelitian ini terdiri dari dua variabel, yaitu variabel terikat (dependent variable) yang merupkan variabel yang dipengaruhi oleh perubahan variabel bebas (independent variabel) yang diberi tanda dengan simbol Y dan variabel bebas (independent variable) merupakan variabel yang bebas berubah dan perubahannya akan mempengaruhi variabel terikat (dependent variable) yang diberi tanda symbol X.Variabel yang dimaksudkan dalam penelitian ini adalah :

\section{a. Pendapatan (Y)}

Pendapatan petani sawit adalah sejumlah uang yang diterima dari hasil penjualan tandan buah kelapa sawit. Pendapatan yang dimaksudkan dalam penelitian ini adalah pendapatan bersih petani sawit selama satu bulan dan dihitung dalam (satuan rupiah).

b. Modal $\left(\mathrm{X}_{1}\right)$

Modal petani sawit adalah Jumlah uang yang dikeluarkan oleh petani sawit. Modal yang dimaksud disini adalah uang, bibit dan pupuk lainnya yang dihitung dalam (satuan rupiah).

c. Luas lahan $\left(\mathrm{X}_{2}\right)$

Luas Lahan yang di miliki petani sawit dalam satuan hektar namun akan di setarakan dengan satuan rupiah yang sangat mempengaruhi tingkat kesehteraan petani sawit di Kecamatan Gunung Meriah Kabupaten Aceh Singkil yang di ukur dalam luas hektar tanah tersebut yaitu (satuan Rupiah).

\section{METODE PENELITIAN}

\section{Metode Analisis Data}

Data yang diperoleh dari responden, kemudian di tabulasi dan diolah dengan menggunakan rumus persentase yang berguna untuk melihat kecenderungan-kecenderungan indikator dari masing-masing indikator. Selanjutnya untuk mengukur besaran dampak dari variabel-variabel, maka data dianalisis dengan menggunakan persamaan regresi berganda ( suharsimi, 2009)

$$
\mathrm{Y}=\mathrm{a}+\mathrm{b} \mathrm{X}_{1}+\mathrm{b} \mathrm{X}_{2}+\mathrm{e}
$$

$\mathrm{Y} \quad=$ Pendapatan (Rupiah)

$\mathrm{X} 1=$ Modal $($ Rupiah $)$
X2 = Luas Lahan (Rupiah)

$\mathrm{a}=$ Konstanta

$\mathrm{b} \quad=$ Koefesien yang dicari

e $\quad=$ standar error

\section{HASIL PENELITIAN DAN PEMBAHASAN}

\section{Hasil Penelitian}

Tabel 1.2

Hasil Analisi Liner Berganda

\begin{tabular}{|c|c|c|c|c|}
\hline \multicolumn{5}{|c|}{ Dependent Variable: PENDAPATAN } \\
\hline \multicolumn{5}{|c|}{ Date: 04/11/18 Time: 05:01 } \\
\hline \multicolumn{5}{|l|}{ Sample: 196} \\
\hline \multicolumn{5}{|c|}{ Included observations: 96} \\
\hline Vaniable & Coefficient & Std. Error & t-Statistic & Prob. \\
\hline $\mathrm{C}$ & -49525.84 & 181087.4 & -0.273491 & 0.7851 \\
\hline MODAL & 0.218259 & 0.096784 & 2.255109 & 0.0265 \\
\hline LUAS_LAHAN & 0.032164 & 0.004119 & 7.809681 & 0.0000 \\
\hline R-squared & 0.572257 & Mean dependent var & & 1729167. \\
\hline Adjusted R-squared & 0.563058 & S.D. dependent var & & 1009550. \\
\hline S.E. of regression & 667328.9 & Akaike info criterion & & 29.69071 \\
\hline Sum squared resid. & $4.14 \mathrm{E}+13$ & Schwarz criterion & & 29.77084 \\
\hline Log likelihood & -1422.154 & Hannan-Quinn criter. & & 29.72310 \\
\hline F-statistic & 62.21005 & Durbin-Watson stat & & 1.876174 \\
\hline $\operatorname{Prob}$ (F-statistic) & 0.000000 & & & \\
\hline
\end{tabular}

$Y=-49525.84+0.218259 X 1+0.032164 X 2+e$

Dari hasil regresi diatas menunjukkan nilai konstanta adalah -49.525.84 yang berarti bahwa, apabila modal dan luas lahan dianggap konstan maka pendapatan petani sawit adalah sebesar 49.525.84 rupiah. Maksudnya, tanpa modal dan luas lahan maka pendapatan petani sawit di Kecamatan GunungMeriah adalah minus 49.525.84 rupiah. Koefesien Regresi untuk modal (X1) adalah sebesar Rp 0.218259 yang berarti bahwa apabila ditambahnya modal sebesar Rp 100.000-, maka pendapatan akan meningkat sebesar Rp 21.8259. dengan asumsi variabel lain dianggap tetap. Koefesien regresi untuk luas lahan 
(X2) sebesar 0.032164 yang berarti bahwa apabila adanya tambahan harga luas lahan sebesar Rp 100.000 maka pendapatan petani sawit akan meningkat sebesar 3.2164.

\section{Gambar 1}

\section{Hasil Uji Normalitas}

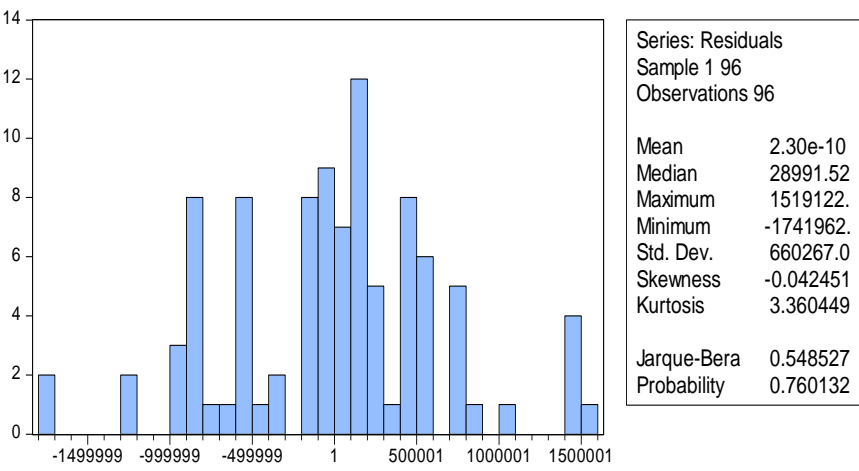

Hasil dari uji normalitas pada gambar 4.4 bahwa nilai probabilitas sebesar $(0.760132)>0,05$ maka dapat disimpulkan bahwa nilai rasidual berdistribusi normal

Tabel 1.3

Hasil Uji Heteroskedastisitas

\begin{tabular}{llll}
\hline \hline F-statistic & 1.771869 & Prob. F(5,90) & 0.1266 \\
Obss*R-squared & 8.603104 & Prob. Chi-Square(5) & 0.1260 \\
Scaled explained SS & 9.528910 & Prob. Chi-Square(5) & 0.0897 \\
& & & \\
\hline \hline
\end{tabular}

Sumber: Data diolah (2018)

Untuk mendeketksi ada tidaknya Heteroskedastisitas atau tidak maka dengan membandingkan nilai R-squared dan 0,05:

a. Jika nilai R-squared > 0,05, maka lolos uji Heteroskedastisitas

b. Jika nilai R-squared $<0,05$, maka tidak lolos uji Heteroskedastisitas

Dari hasil di atas bahwa nilai obs*R-squared untuk hasil estiamasi dari obs*R-squared adalah sebesar 0.1260. karena nilai R-squared (0.1260) > 0,05 maka dapat disimpulkan model diatas lolos dari uji Heteroskedastisitas.

Tabel 1.4

\section{Uji Multikolinearitas}

Variance Inflation Factors

Date: 04/30/18 Time: 08:26

Sample: 196

Included observations: 96

\begin{tabular}{cccc}
\hline Variable & $\begin{array}{c}\text { Coefficient } \\
\text { Variance }\end{array}$ & $\begin{array}{c}\text { Uncentered } \\
\text { VIF }\end{array}$ & $\begin{array}{c}\text { Centered } \\
\text { VIF }\end{array}$ \\
\hline C & $3.28 \mathrm{E}+10$ & 7.069162 & NA \\
MODAL & 0.009367 & 3.321127 & 1.451455 \\
LUAS_LAHAN & $1.70 \mathrm{E}-05$ & 10.14889 & 1.451455 \\
\hline Sumber: Data diolah_2018 & & &
\end{tabular}

Berdasarkan tabel 4.6 nilai centered VIF di bawah 10 dan menunjukkan tidak terjadi, multikolinearitas anatar variable bebas dalam model regrsi. Hasil olah data di ketahui bahwa nilai centered FIV variabel Modal $\left(\mathrm{X}_{1}\right)$ sebesar 1.451455 dan luas lahan $\left(\mathrm{X}_{2}\right)$ sebesar 1.451455 . maka dari itu apa bila nilai VIF tidak lebih besar dari 10 maka model tersebut dapat dikatakan terbebas dari multikolinearitas.

Tabel 1.5

Hasil Uji parsial (Uji t)

\begin{tabular}{|c|c|c|c|c|c|}
\hline \multicolumn{5}{|c|}{ Variabel Dependen Parsial (Pendapatan) } \\
\hline Nama & t-statistik & t-tabel & Prob & Keterangan & hipotesis \\
Variabel & & & & & \\
\hline Modal & 2.255109 & & 0.0265 & signifikan & Diterima \\
\hline Luas lahan & 7.809681 & \multirow{2}{*}{1.661} & 0.0000 & signifikan & Diterima \\
\cline { 1 - 2 } \cline { 4 - 6 } & & & & \\
\hline
\end{tabular}

Modal memiliki nilai thitung sebesar 2.255109 dengan nilai signifikan 0.0265 sementara nilai ttabel dengan $(\mathrm{df})=\mathrm{n}-\mathrm{k}(96-3=63)$ pada $\alpha=0.05$ di peroleh nilai sebesar 1.661 , maka thitung > ttabel yaitu 2.255109>1.661 dengan nilai signifikan $<0.05$ maka keputusannya adalah $\mathrm{H}_{0}$ dan menerima $\mathrm{Ha}$, yang berati bahwa secara parsial modal berpengaruh secara signifikan terhadap pendapatan petani sawit di Kecamatan Gunung Meriah Kabupaten Aceh Singkil.

Kemudian variabel luas lahan memiliki thitung sebesar 7.809681 dengan nilai signifikasi 0.0000 , sementara nilai ttabel dengan $(\mathrm{df})=\mathrm{n}-\mathrm{k}$ (96-3=93) pada $\alpha=0.05$ di peroleh nilai sebesar 1.661 maka thitung > ttabel yaitu 7.809681>1.661 
dengan nilai signifikan $<0.05$ maka keputusannya adalah hipotesis menolak Ho dan menerima $\mathrm{Ha}$ yan berarti bahwa secara parsial luas lahan berpengaruh secara signifikan terhadap pendapatan petani sawit di kecamatan Gunung Meriah Kabupaten Aceh Singkil.

\section{Pembuktian Secara Simultan (Uji F)}

Tabel 1.6

Hasil Uji Simultan (Uji F)

\begin{tabular}{|l|l|l|l|l|}
\hline F-Statistik & F-tabel & Prob & Keterangan & Hipotesis \\
\hline 62.21005 & 3.09 & 0 & signifikan & Diterima \\
\hline
\end{tabular}

Sumber:Data diolah,2018

Maka dapat di lihat bahwa Fhitung sebesar 62.21005 dengan nilai siginifikan sebesar 0.0000 pada taraf 95\%. Sedangkan Ftabel V1 = n-k (963=93) dan V2 = k-1 (3-1=2) di peroleh nilai sebesar 3,16 pada $\alpha=0.05$ maka Fhitung $>$ Ftabel, yaitu $62.2>3,16$ atau nilai signifikasinya $<0.05$, maka keputusannya adalah hipotesis menolak Ho dan menerima Ha, artinya secara serempak atau bersama-sama modal dan luas lahan, berpengaruh secara signifikan terhadap pendapatan petani sawit di Kecamatan Gunung Meriah Kabupaten Aceh Singkil.

\section{Koefesien Korelasi R}

Dalam penelitian ini yang menjelaskan tentang mengenai analisis korelasi yaitu suatu cara untuk mengehatui kuat atau tidaknya hubungan antara $\mathrm{X}$ dan $\mathrm{Y}$ apa bila di nyatakan dengan fungsi liner. Koefesien korelasi $(\mathrm{R})$ adalah $\mathrm{R}=0.57225$ pengaruh positif terhadap variabel Modal $\left(\mathrm{X}_{1}\right)$, dan Luas lahan $\left(\mathrm{X}_{2}\right)$ terhadap pendapatan $(\mathrm{Y})$ petani sawit di Kecamatan Gunung Meriah Kabupaten Aceh Singkil.

\section{Koefesien Determinasi $\left(\mathbf{R}^{2}\right)$}

\section{Tabel 1.7}

Hasil Uji Adjusted R Square

Sumber:Data Diolah, 2018
Selanjutnya dari t tabel juga dapat di ketahui koefesien determinasi $\left(\mathrm{R}^{2}\right)$ sebesar $=0.563058$ atau 5630\%, artinya pengaruh variabel Modal $\left(\mathrm{X}_{1}\right)$, dan Luas lahan $\left(\mathrm{X}_{2}\right)$ terhadap pendapatan petani sawit di Kecamatan Gunung Meriah Kabupaten Aceh Singkil adalah sebesar 56,30\% atau sisanya 43,7 .

\section{Pembahasan}

\section{Pengaruh Modal Terhadap Pendapatan Petani Sawit}

Berdasarkan hasil pengujian bahwa modal berpengaruh secara signifikan terhadap pendapatan petani sawit di kecamatan Gunung Meriah Kabupaten Aceh Singkil. Hal ini ditunjukkan dengan nilai t-hitung sebesar 2.255109 dengan nilai signifikasi 0.0265 sementara nilai $\mathrm{t}_{\text {tabel }}$ dengan $(\mathrm{df})=\mathrm{n}-\mathrm{k}(96-3=93)$ pada $\alpha=0.05$ di peroleh nilai sebesar 116.51105 maka $t_{\text {hitung }}>t_{\text {tabel, }}$ yaitu $2.255109>116.51105$. jika modal $\left(\mathrm{X}_{1}\right)$, ditingkatkan $\mathrm{Rp}$ 100.000.- maka pendapatan akan meningkat sebesar Rp 21.8259.

\section{PENUTUP}

\section{Kesimpulan}

1. Petani sawit di Kecamatan Gunung Meriah Kabupaten Aceh Singkil secara parsial dijumpai bahwa variabel Modal dan Luas Lahan berpengaruh secara signifikan terhadap pendapatan para petani sawit

2. Secara Simultan menyatakan bahwa variable Modal dan Luas Lahan bersama-sama (serempak) berpengaruh secara signifikan terhadap pendapatan para petani sawit tersebut.

3. Berdasarkan dari Uji Asumsi Klasik yang telah di lakukan, Normalitas, Heterokedastisitas, dan Multikoliearitas pada data yang di uji sudah terbebas dari berbagai Adjusted R Squared $=0.563058$ 
gejala asumsi klasik atau tidak terjadi masalah.

\section{Saran}

Berdasarkan dari hasil penelitian dan kesimpulan di atas, maka penulis memberikan beberapa saran sebagai berikut:

1. Untuk para petani sawit yang memilik Modal dan Luas Lahan agar lebih memaksimalkan lagi dalam pengelolaan untuk Luas Lahan agar hasil dari tanaman kelapa sawit lebih maksimal dan bisa meningkatkan kesejahteraan petani dengan demikian juga akan meningkat pendapatannya.

2. Bagi Pemerintah Kabupaten Aceh Singkil dan Kecamatan Gunung Meriah, penulis menyarankan untuk dapat mengupayakan pembinaan terhadap para petani sawit dan pelatihan untuk pengembangan potensi untuk lebih meningkatkan lagi perekonomian masyarakat dan sejahtera nantinya sekaligus pendapatan petani sawit bisa berambah lagi.

3. Bagi peneliti selanjutnya yang ingin meneliti tentang Modal, Luas Lahan yang mempengaruhi pendapatan petani sawit. Ada baiknya menambah variabel-variabel lain untuk di teliti, karena sebenarnya cukup banyak yang bisa di jadikan faktor- faktor lain yang mempengaruhi pendapatan petani sawit.

\section{DAFTAR PUSTAKA}

Al-bukhari. (n.d.).

Al-jurjani, S. A. bin M. (2001). Az Zuhaili.

Al-Qur'an surah An-Nahl ayat 97.
Al-Qur'an surah An-Nisa ayat 9

Al-qur'an Surat Al-Baqarah ayat 279. (n.d.).

Ambadar, jaky. (2010). CRS Dalam Praktik Di Indonesia. jakarta: PT. Alexmedia.

Azwar, Syaifuddin .(2004). Metode Penelitian. Penerbit Pustaka Belajar. Yogyakarta

Badan pusat statistik 2004

Dayu Maharani. (2006). perbandingan pola konsumsi pada kalangan mahasiwa yag indeks di kota surakarta.

Dina amluis.(2013). pengaruh biaya Produksi dan Harga Jual Beli Tandan Buah Segar (TBS) Kelapa Sawit Terhadap Pendapatan Petani di KUD Lingkung AUR II Kecamatan Pasaman Kabupaten Pasaman Barat. Universitas Andalas

Dinas Kehutanan Dan Perkebunan Kabupaten

Aceh Singkil. (n.d.).

fauzi y, widiastuti, sasyawibawa dan r. (2006). kelapa sawit budidaya,pemanfaatan hasil dan limbah analisis usaha dan pemasaran. jakarta: penebar swadaya.

Gunung Meriah Dalam Angka. (n.d.).

Ghozali. (2005) Uji Maltivariat Test. Alfabet Bandung

Gurajati, Damodar. (2006). Dasar-Dasar Ekonomimetrika. Jakarta .Erlangga.

kasmir. (2012). bank dan lembaga keuangan lainnya. jakarta: PT.Raja Grafindo Persada.

Kuncoro. Mudrajad. (20011) Metode Kuantitaif teori dan Aplikasi Untuk Bisnis dan Ekonomi. UUP STIM. Yogyakarta

Maharani. Dayu. (2006) Pendidikan Pola Konsumsi Pada Kalangan Mahasiswa Yang Indek Di Kota Surakarta

Mubyanto. (2008). Kewirausahaan. jakarta: yudistira. 
Mubyarto. (n.d.). pengantar ekonomi pertanian edisi ketiga. jakarta: LP3ES.

Pusat Pengkajian dan Pengembangan Ekonomi Islam.(2008). jakarta: PT. Raja Grafindo Persada

Priyatno. (2010). teknik mudah dan cepat melakukan analisis data. penelitian dengan SPSS dan tanya jawab Ujian Pendadaran. yogyakarta: PT. Rineka cipta.

Singarimbun. (2006). Metode Penelitian Survai. jakarta: Edisi Pertama.

Sugiyono. (2007). metode penelitian kuantitatif, kualitatif Dan R\&D. Bandung: Alfabeta.

Suharsimi. Arikunto. (2009) Manajemen Penelitian. jakarta: Rosdakarya

Sukirno, S. (2002). Pengantar Teori Mikroekonomi. Penerbit PT.Raja Grafindo peresada, Jakarta. jakarta.

Supratno. j (2006) Pengukuran Tingkat Kepuasan Pelanggan Untuk Menaikan Bangsa Pasar. jakarta: PT Rineka Cipta

UU.No.11 tahun . 2009 tentang kesejahteraan sosial. (n.d.). 